\title{
A case of a patient treated with percutaneous edge-to-edge mitral valve repair, percutaneous left atrial appendage occlusion and implantable cardioverter-defibrillator
}

\author{
Corresponding author: \\ Wioleta Stolarek \\ Department of Pharmacology \\ and Therapeutics, Faculty of Medi- \\ cine, Collegium Medicum in Bydgo- \\ szcz, Nicolaus Copernicus \\ University, 9 Sklodowskiej-Curie Street, \\ 85-094 Bydgoszcz, Poland, P \\ hone/fax number: +48525853584 \\ e-mail: wioletaplazuk@02.pl \\ Medical Research Journal 2019; \\ Volume 4, Number 3, 189-191 \\ 10.5603/MRJ.a2019.0028 \\ Copyright ( 12019 Via Medica \\ ISSN 2451-259
}

\begin{abstract}
The article presents the case of a 55-year-old woman who suffered from anterior myocardial infarction and chronic complications of the underlying disease, heart failure with reduced left ventricular ejection fraction, severe secondary mitral regurgitation, and paroxysmal atrial fibrillation. Due to the severity of symptoms, which persisted despite the optimal pharmacotherapy, after exclusion of reversible causes, the patient was qualified for different advanced percutaneous treatment methods. Within two years from the onset of the disease, three percutaneous procedures were performed: mitral valve correction with the MitraClip system, left atrial appendage occlusion using the Watchman system, and implantation of cardioverter-defibrillator. Key words: heart failure with reduced ejection fraction, mitral regurgitation, percutaneous edge-to-edge mitral valve repair, left atrial appendage occlusion, implantable cardioverter-defibrillator
\end{abstract}

Med Res J 2019; 4 (3): 189-191

\section{Introduction}

The prevalence of heart failure (HF) concerns $1-2 \%$ of the adult population in developed countries. Many patients have cardiovascular and non-cardiac abnormalities that may result in HF. Therefore, the identification of these abnormalities should be part of the diagnostic process, because many of these causes can be reversible [1-4]. Epidemiological data from European studies (ESC-HF pilot study) indicate that the 12-month total HF mortality rate in hospitalized patients or those under outpatient care was $17 \%$ and $7 \%$, respectively, and the 12-month hospitalization rates were $44 \%$ and $32 \%$ in both groups. In $\mathrm{HF}$ patients most deaths are caused by cardiovascular events. Sudden deaths and deaths related to the disease exacerbation are most common in this group of patients [5].

\section{The acute anterior myocardial infarction}

The 55-year-old patient was admitted to the Department of Cardiology at University Hospital in Bydgoszcz on December 15,2014 , due to the acute anterior myocardial infarction. The patient had no history of chronic diseases, apart from long-term smoking. The urgent primary percutaneous coronary intervention of the left anterior descending artery with implantation of drug-eluting stent (DES) was performed. The procedure was complicated by sudden cardiac arrest in the mechanism of asystole with effective cardiopulmonary resuscitation. In addition, during the hospitalization, the first atrial fibrillation (AF) episode occurred (according to the $\mathrm{CHA}_{2} \mathrm{DS}_{2}$-VASc score -4 points, according to the HAS-BLED score -1 point). Echocardiographic examination revealed: impaired left ventricular systolic function with reduced left ventricular ejection fraction (LVEF) of $20-25 \%$, diastolic relaxation dysfunction, severe secondary mitral regurgitation with vena contracta (Vc) of $0.9 \mathrm{~cm}$, severe tricuspid valve regurgitation, systolic pulmonary artery pressure (SPAP) of $52 \mathrm{~mm} \mathrm{Hg}$, features of pulmonary hypertension, enlargement of all heart chambers: left atrium (LA) $51 \mathrm{~mm}$, left ventricular end-systolic diameter (LVESD) of $50 \mathrm{~mm}$, left ventricular end-diastolic diameter (LVEDD) of $60 \mathrm{~mm}$, right ventricle (RV) of $40 \mathrm{~mm}$, akinetic apical aneurysm, akinesis of the other segments of anterior and interventricular 
septum. Vitamin K antagonist (warfarin) per patient's choice was introduced to the therapy. The patient was discharged in functional class II according to New York Heart Association (NYHA) with a further therapeutic plan including among others echocardiographic control.

\section{Decompensation of chronic heart failure}

Subsequent hospitalization of the patient was associated with episodes of decompensation of chronic heart failure up to NYHA class IV with B-type natriuretic peptide (BNP) $>2000 \mathrm{pg} / \mathrm{mL}$. The ECG on admission revealed sinus rhythm $88 / \mathrm{min}$, the small progression of $R$ waves in V1-V4, no ST-T changes, QRS complex $<110 \mathrm{~ms}$. Echocardiographic parameters were the same as previously. The patient underwent coronary angiography which has not shown any new lesions in the coronary arteries or restenosis. After the Heart Team consultation, the patient was disqualified from the surgical treatment of mitral valve regurgitation. Therefore, the patient underwent transthoracic and transesophageal echocardiography (TEE) to fully assess mitral valve morphology. TEE revealed severe mitral regurgitation wave with $\mathrm{Vc}$ of $0.9 \mathrm{~cm}$, thickened leaflets of mitral valve with features of limited restriction, mitral wave area (MVA) of $3.8 \mathrm{~cm} 2$, coaptation depth of $0.8 \mathrm{~cm}$, coaptation height of $0.6 \mathrm{~cm}$, length of anterior leaflet $2.6 \mathrm{~cm}$, length of posterior leaflet $1.6 \mathrm{~cm}$, severe tricuspid regurgitation wave, and thrombus-free left atrium appendage.

\section{Percutaneous edge-to-edge mitral valve correction}

During the next hospitalization approximately a year after myocardial infarction, percutaneous edge-to-edge mitral valve correction with the use of the MitraClip system was performed without periprocedural complications. Two clips were implanted, resulting in a reduction of the mitral regurgitation wave. In the follow-up echocardiography, two MitraClip sets were found in the normal position without device-related thrombi, and two narrow mitral regurgitation waves were observed (Vc $0.4-0.5 \mathrm{~cm}$ ). Patients general condition improved after the procedure. Due to the above-mentioned procedure, dual antiplatelet therapy consisting of aspirin $75 \mathrm{mg}$ once daily and clopidogrel $75 \mathrm{mg}$ once daily, with warfarin (the patient continued to refuse non-vitamin $\mathrm{K}$ antagonist anticoagulation due to financial reasons).

\section{Percutaneous left atrial appendage occlusion}

Another scheduled hospitalization was associated with routine follow-up after the previous procedure. Lab- oratory tests revealed a non-therapeutic International Normalized Ratio (INR) index of 6.5 and normocytic anaemia ( $\mathrm{Hgb} 9.0 \mathrm{~g} / \mathrm{dL}$, MCV $81.5 \mathrm{fL}$ ). According to the patient from the beginning of the anticoagulation treatment, she was not able to obtain stable INRs and periodically reported tarry stools. The time in the therapeutic range of INR was rated at $<60 \%$ for this patient. The gastroduodenoscopy revealed a non-bleeding vessel (Forrest Ila) in the duodenum. Recalculated $\mathrm{CHA}_{2} \mathrm{DS}_{2}$-VASc score was 4 points, and HAS-BLED score was 3 points. The patient was qualified for left atrial appendage occlusion. Intraprocedural TEE did not reveal thrombi in the left atrial appendage, and the percutaneous occlusion of the left atrial appendage with the Watchman system was performed without complications. After the procedure warfarin was stopped, while dual antiplatelet therapy was maintained. Control echocardiographic studies (transthoracic and transesophageal) performed after the procedure and during planned controls showed the correct position of the occluder in the left atrial appendage without residual leaks or device-related thrombi. This examination also revealed the correct position of the previously implanted MitraClip sets and moderate double-stream mitral regurgitation wave $(\mathrm{Vc} 0.6 \mathrm{~cm})$. The remaining parameters were comparable to the previous study, with no improvement in LVEF which remained at the level of $20-25 \%$.

\section{Implantation of the cardioverter- defibrillator}

Available ECG monitoring (telemetry or ECG Holter) did not reveal any complex ventricular arrhythmias. Due to the clinical picture (post-infarction cardiomyopathy, LVEF $\leq 35 \%$, optimal medical therapy (OMT) for more than 3 months (Tab. 1), without QRS complex $\geq 130 \mathrm{~ms}$ ), the patient was qualified for implantation of transvenous cardioverter-defibrillator (ICD) for the primary prevention of sudden cardiac death. During the next hospitalization, ICD (Medtronic Protecta VR, Medtronic 6935M-55 cm lead) was implanted in the left subclavian area. The procedure

Table 1. Optimal pharmacotherapy

Drug and dose [mg]

Aspirin 75 once daily

Ramipril 2.5 once daily

Carvedilol 25 twice daily

Furosemide 40 twice daily

Eplerenone 50 once daily

Atorvastatin 20 once daily 
Table 2. Selected ESC recommendations.

\begin{tabular}{|c|c|c|c|}
\hline Recommendations & Class & Level & References \\
\hline $\begin{array}{l}\text { In patients with severe secondary mitral regurgitation and LVEF }<30 \% \text { who remain } \\
\text { symptomatic despite optimal medical management (including cardiac resynchronization } \\
\text { therapy (CRT) if indicated) and who have no option for revascularization, the Heart Team } \\
\text { may consider a percutaneous edge-to-edge procedure or valve surgery after careful } \\
\text { evaluation for a ventricular assist device or heart transplant according to individual patient } \\
\text { characteristics }\end{array}$ & Ilb & $\mathrm{C}$ & 6 \\
\hline $\begin{array}{l}\text { Left atrial appendage (LAA) occlusion may be considered for stroke prevention in patients } \\
\text { with AF and contra-indications for long-term anticoagulant treatment (e.g. those with a } \\
\text { previous life-threatening bleed without a reversible cause) }\end{array}$ & $\mathrm{Ilb}$ & $\mathrm{B}$ & $7-9$ \\
\hline Primary prevention & I & A & $10-12$ \\
\hline $\begin{array}{l}\text { An ICD is recommended to reduce the risk of sudden death and all-cause mortality in } \\
\text { patients with symptomatic HF (NYHA Class II-III), and an LVEF } \leq 35 \% \text { despite } \geq 3 \text { months } \\
\text { of OMT, provided they are expected to survive substantially longer than one year with good } \\
\text { functional status, and they have: } \\
\text { - ischaemic heart disease (IHD) unless they have had a myocardial infarction in the prior } \\
40 \text { days }\end{array}$ & & & \\
\hline
\end{tabular}

was carried out without any complications. The control echocardiography did not show any significant changes compared with the previous study.

\section{Conclusions}

The medical history of the patient shows the possibilities of combining OMT and modern invasive methods of treatment in cardiology. Due to the severity of the patient's disease, appropriate decisions were made regarding the time and type of advanced therapy methods according to European Society of Cardiology (ESC) guidelines (Tab. 2). This is probably one of the few patients in whom, two years after the beginning of the disease, three different percutaneous treatment methods were used with optimal results. Moreover, since the implementation of the above-mentioned methods, the patient was not hospitalized due to cardiovascular diseases. The patient is still under the control of the outpatient clinic.

\section{Disclosure of interest}

The authors declare that they have no conflict of interest.

\section{References}

1. Mosterd A, Hoes AW. Clinical epidemiology of heart failure. Heart. 2007; 93(9): 1137-1146, doi: 10.1136/hrt.2003.025270, indexed in Pubmed: 17699180.

2. Redfield MM, Jacobsen SJ, Burnett JC, et al. Burden of systolic and diastolic ventricular dysfunction in the community: appreciating the scope of the heart failure epidemic. JAMA. 2003; 289(2): 194-202, doi: 10.1001/jama.289.2.194, indexed in Pubmed: 12517230.
3. Bleumink GS, Knetsch AM, Sturkenboom MC et al. Quantifying the heart failure epidemic: prevalence, incidence rate, lifetime risk and prognosis of heart failure The Rotterdam Study. Eur Heart J. 2004; 25(18): 1614-1619, doi: 10.1016/j.ehj.2004.06.038, indexed in Pubmed: 15351160

4. Ceia F, Fonseca C, Mota T, et al. EPICA Investigators. Prevalence of chronic heart failure in Southwestern Europe: the EPICA study. Eur J Heart Fail. 2002; 4(4): 531-539, doi: 10.1016/s1388-9842(02)00034-x, indexed in Pubmed: 12167394

5. Maggioni AP, Dahlström U, Filippatos G, et al. Heart Failure Association of the European Society of Cardiology (HFA). EURObservational Research Programme: regional differences and 1-year follow-up results of the Heart Failure Pilot Survey (ESC-HF Pilot). Eur J Heart Fail. 2013; 15(7): 808-817, doi: 10.1093/eurjhf/hft050, indexed in Pubmed: 23537547

6. Baumgartner H, Falk V, Bax JJ, et al. ESC Scientific Document Group, ESC Scientific Document Group. 2017 ESC/EACTS Guidelines for the management of valvular heart disease. Eur Heart J. 2017; 38(36): 2739-2791, doi: 10.1093/eurheartj/ehx391, indexed in Pubmed: 28886619

7. Holmes DR, Kar S, Price MJ et al. Prospective randomized evaluation of the Watchman Left Atrial Appendage Closure device in patients with atrial fibrillation versus long-term warfarin therapy: the PREVAIL trial. J Am Coll Cardiol. 2014; 64(1): 1-12, doi: 10.1016/j.jacc.2014.04.029, indexed in Pubmed: 24998121.

8. Holmes DR, Doshi SK, Kar S, et al. Left Atrial Appendage Closure as an Alternative to Warfarin for Stroke Prevention in Atrial Fibrillation: A Patient-Level Meta-Analysis. J Am Coll Cardiol. 2015; 65(24): 2614-2623, doi: 10.1016/j.jacc.2015.04.025, indexed in Pubmed: 26088300.

9. Reddy VY, Möbius-Winkler S, Miller MA, et al. Left atrial appendage closure with the Watchman device in patients with a contraindication for oral anticoagulation: the ASAP study (ASA Plavix Feasibility Study With Watchman Left Atrial Appendage Closure Technology). J Am Coll Cardiol. 2013; 61(25): 2551-2556, doi: 10.1016/j.jacc.2013.03.035, indexed in Pubmed: 23583249

10. Moss AJ, Zareba W, Hall WJ, et al. Multicenter Automatic Defibrillator Implantation Trial II Investigators. Prophylactic implantation of a defibrillator in patients with myocardial infarction and reduced ejection fraction. N Engl J Med. 2002; 346(12): 877-883, doi: 10.1056/NEJMoa013474, indexed in Pubmed: 11907286

11. Desai AS, Fang JC, Maisel WH, et al. Implantable defibrillators for the prevention of mortality in patients with nonischemic cardiomyopathy: a meta-analysis of randomized controlled trials. JAMA. 2004; 292(23): 2874-2879, doi: 10.1001/jama.292.23.2874, indexed in Pubmed: 15598919.

12. Bardy G, Lee K, Mark D, et al. Amiodarone or an Implantable Cardioverter-Defibrillator for Congestive Heart Failure. New England Journal of Medicine. 2005; 352(3): 225-237, doi: 10.1056/nejmoa043399. 